\title{
The use of SmartBox container for agrobusiness logistic processes optimization
}

\author{
Anatoly Korotky ${ }^{1}$, Sergey Popov ${ }^{1, *}$, Galina Galchenko ${ }^{1}$, Julianna Marchenko ${ }^{1}$ and Dmitriy \\ Drozdov $^{2}$ \\ ${ }^{1}$ Don State Technical University, 1, Gagarin sq., 344003, Rostov-on-Don, Russia \\ ${ }^{2}$ Southern Federal University, 105/42, Bolshaya Sadovaya st., 344006, Rostov-on-Don, Russia
}

\begin{abstract}
The problems of agrobusiness transport and logistics processes optimization using SMART BOX container and administration software package, and optimization of container delivery routes are considered. Current software product can be used as a computer laboratory for training students in the specialty "Organization of transport processes."
\end{abstract}

\section{Introduction}

The use of modern logistics tools together with applied software products will create more favorable working conditions for agribusiness wholesale distribution centers (ORCs). Currently, ORCs are widely used in the world [1-6].

The structure of distribution centers is as follows: USA $-24 \%$, China $-14 \%$, Japan $6 \%$, United Kingdom $-4 \%$, Germany $-4 \%$, Netherlands, France, Iran $-2 \%$, Spain, Turkey, Iran, Mexico, Italy - 1\%, other countries - 7\%. In Russia, in 2014, in connection with the rapid development of agricultural cooperatives and the reorientation of consumers to local food products, the program development to create ORCs began.

ORCs are focused on the provision of services for the completion, packaging and delivery of products for retailers, restaurants, fast food chains, etc. The use of robotics in the ORC will allow to collect many individual orders quickly and without errors.

The article proposes to use folding transcontainer (FTC) - transformer SmartBox, designed and created in the production association LLC ICC "Mysl" and an application computer program to optimize the container delivery route. Currently, computer programs are widely used in the world as training laboratories. [1-6]. The proposed software product is also used as a computer laboratory for scientific and educational purposes.

\footnotetext{
*Corresponding author: spopov1957@yandex.ru
} 


\section{Construction and production}

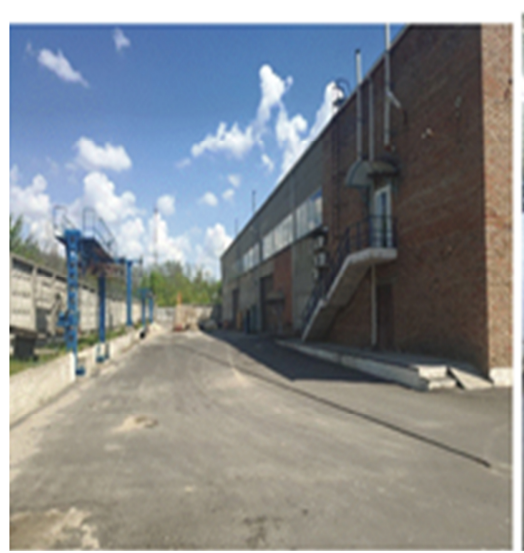

a)
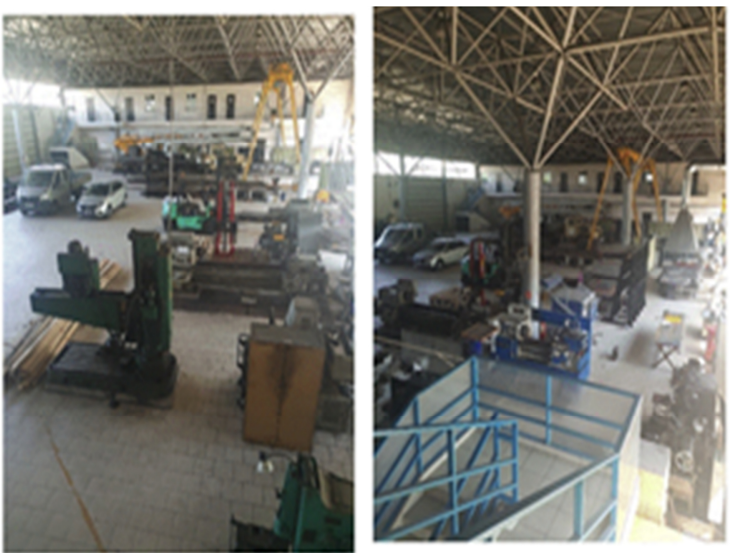

b)

Fig. 1. Production rooms: a) outside, b) inside.

Folding transcontainer automatically and autonomously transformed into both working and folded state.

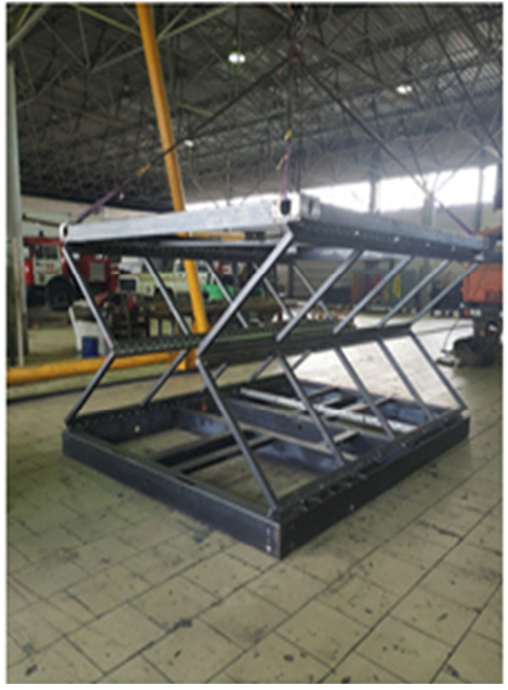

a)

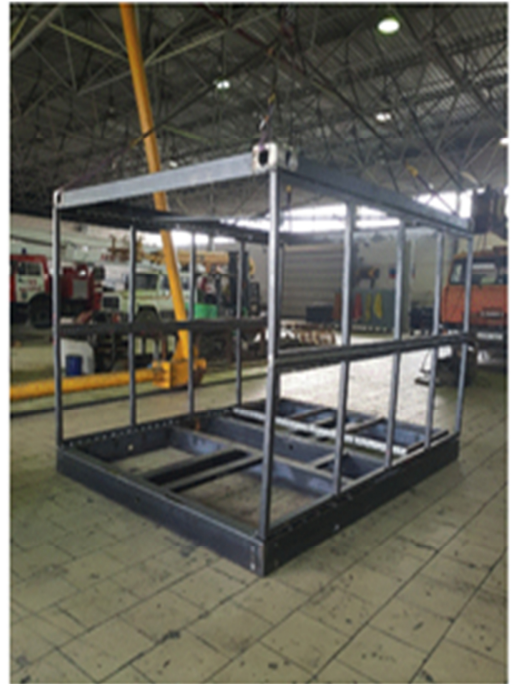

b)

Fig. 2. Production FTC: a) folding housing, b) housing fully open.

Due to balancing system presence on gas springs and solid lubricant coatings [7-13], energy costs are reduced, which makes it possible to automate the transformation process using low-power drive.

The "bag" option made of fabric material or soft impermeable material (flexitank) allows to transport not only piece goods (as in ordinary containers), but also bulk and liquid ones [14-30].

Figure 3 shows fragments of work with FTC SmartBox: folding, loading and unloading of an empty folded FTC SmartBox in a car body, unloading piece goods, moving loaded manipulator to warehouse. 


\section{Container managing}

To manage the container, an information system (IS) of remote administration is used. This IP allows to identify the customer, accept applications, transmit sensor readings about the stock being moved by mass-volume characteristics, including tracking its location in space and time with reference to geodata coordinates (GLONASS, GPS, etc.) on the map server, and remotely safety control during operation.

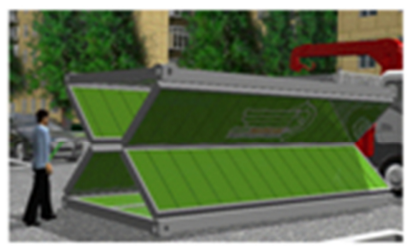

$\boldsymbol{a}$

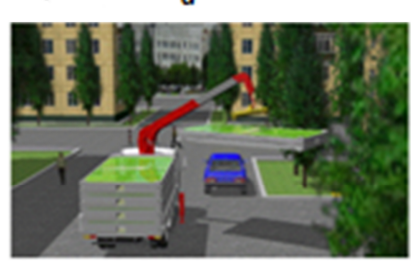

$c$

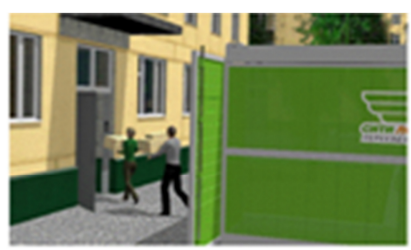

b

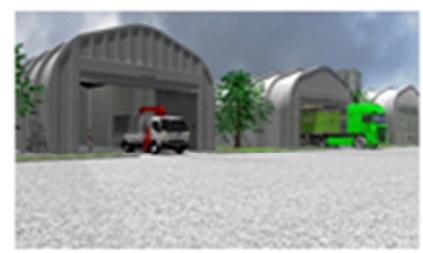

$d$

Fig. 3. Working with SmartBox FTC: a) folding SmartBox FTC, b) unloading piece goods from SmartBox FTC, c) loading and unloading empty folded SmartBox FTC, d) the manipulator moves to the warehouse and unloads SmartBox FTC in stacks.

\section{Delivery route optimization SmartBox FTC}

The software package "OptimRoute" for optimizing delivery route of SmartBox FTC to ORCs and loaded containers to consumers: restaurants, private traders, etc., in urban conditions, developed on the basis of mathematical modeling methods. There were used such methods as: cellular automation method, electrodynamic modeling method, as well as large database of field observations on Rostov-on-Don routes problem sections, taking into account traffic intensity characteristics and traffic congestion. Created database allows manual program control in the absence of the Internet.

Work with the program begins with the preparation of auxiliary files and required libraries binder. To perform these actions, you can use the link: https://drive.google.com/open?id=1ZWNfy30hK0m56M30Dj2Y8ZNM71eKAkfa.

The program works correctly when using the version NET Framework not less 4.7.1. If necessary, the package can be downloaded at https://www.microsoft.com/ru$\mathrm{RU} /$ download/details.aspx?id=56116.

In Library, the data and executable file (exe) must be placed in the same directory. An example of the correct file location is shown at Figure 4. 


\begin{tabular}{|l|rrr|l|}
\hline Fis Debug.zip \\
File Commands
\end{tabular}

Fig. 4. Files for launching the software package "OptimRoute".

To start working with the program, you must run «Bus.exe» file. The possible window menu state after starting is shown at Figures 5,6. We load the map of the city or region with which we will work into the window on the right. We load necessary stops in case of delivery of the FTC or container with the goods to several customers into the window on the left.

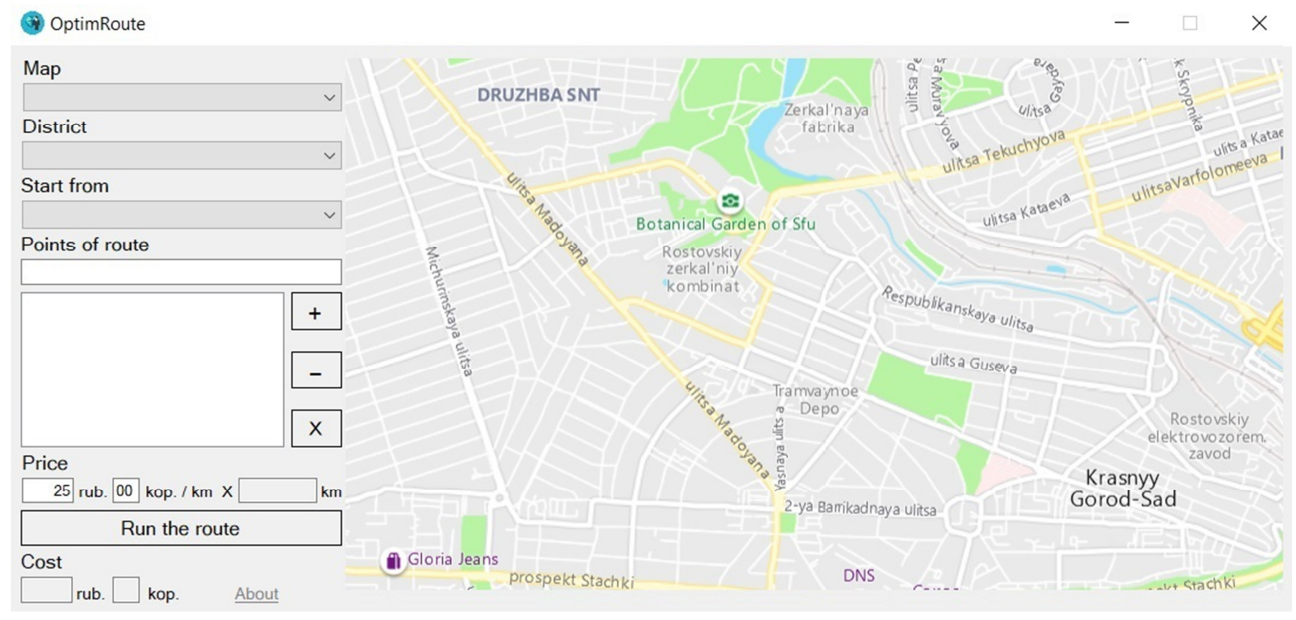

Fig. 5. Download customer data into the "OptimRoute" program: a) window for loading city or district maps b) window for loading addresses of delivery points.

Database stores customers' addresses, necessary stops, which are loaded into the window. The driver is notified of the departure time. 


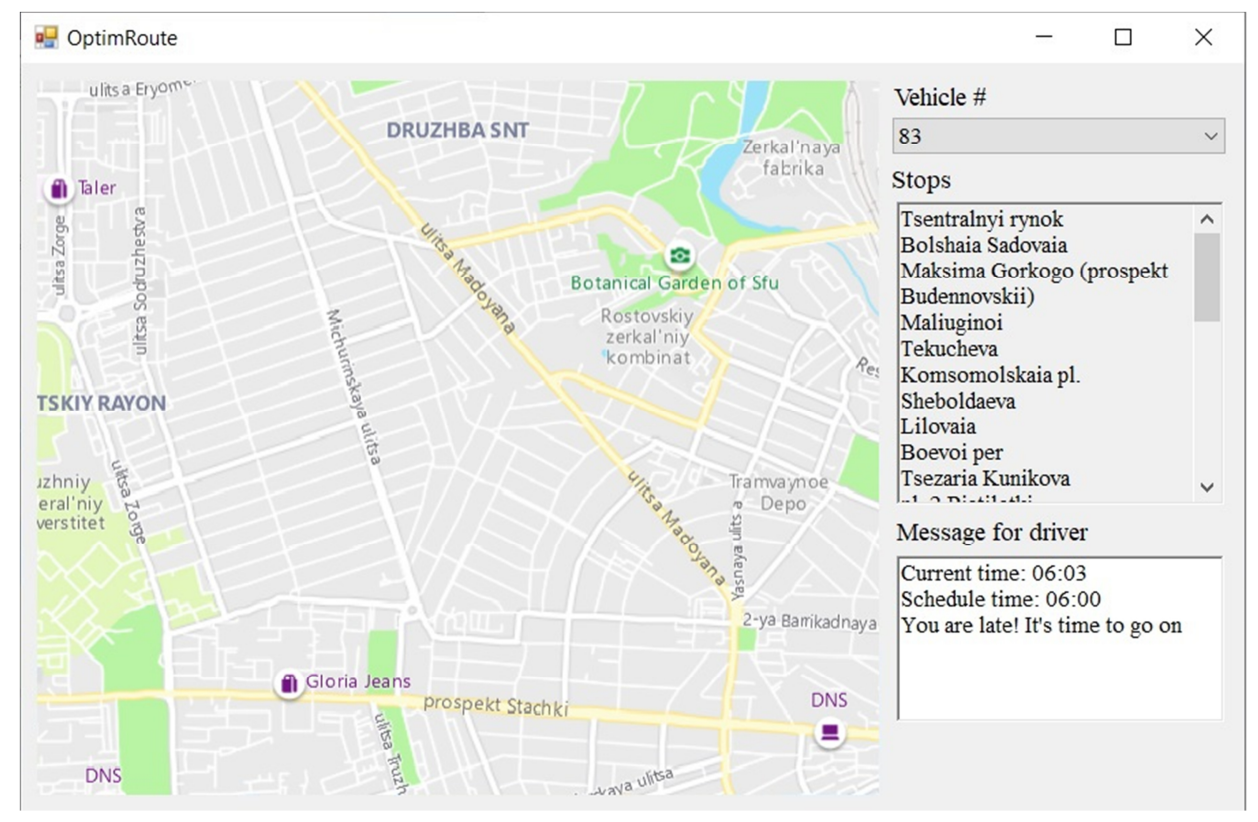

Fig. 6. Program menu of "OptimRoute" for delivery FTC to consumers.

\section{Conclusions}

The use of Smart Box folding transcontainer together with the software package for remote administration and optimization of agricultural products delivery routes effectively optimizes the time costs of transport enterprises, as well as processes related to the human factor - up to $30 \%$, reduces loading / unloading time to 25 , reduces the share empty runs of vehicles and up to $75 \%$ reduces logistics costs for the transport of empty containers.

In the conditions of increasing service and competition between enterprises, the use of Smart Box folding transcontainer will make the work of carriers and agribusiness producers more profitable. In addition, this software product can be used for educational purposes as student laboratory for optimization and modeling of transport processes for students and undergraduates in the field of "Organization of transport processes".

\section{References}

1. L. Rivera, M. Petrie, iJOE 12, 9 (2016)

2. I. Titov, A. Glotov, I. Vlasov, J. Mikolnikov, iJOE 12, 4 (2016)

3. Yi-Han Liu, Yu He, Di He, Run-Long Fan, Li Yao, CAEE 26, 5 (2018)

4. D. Gubsky, A. Kleshchenkov, A. Gubsky, RSEMW, 258-260 ( 2017)

5. A. Lerer, G. Makeeva, G. Galchenko, RSEMW 8792726, 261-264 (2019) doi:10.1109/RSEMW.2019.8792726

6. D. Gubsky, A. Kleschenkov, G. Galchenko, RSEMW, 344-347 (2019) doi:10.1109/RSEMW.2019.8792757

7. V.V. Ivanov, S.I. Popov, E.M. Selemeneva, N.T. Babazhanov, AIP Conference Proceedings 2188, 020015 (2019) doi.org/10.1063/1.5138389 
8. V.V. Ivanov, S.I. Popov, Ju.V. Marchenko, E.V. Marchenko, N.S. Dontsov, S.A. Timofeev, IOP Conference Series: Earth and Environmental Science 403, 012115 (2019) doi:10.1088/1755-1315/403/1/012115

9. A.A. Korotky, E.V. Marchenko, V.V. Ivanov, S.I. Popov, Ju.V. Marchenko, N.S. Dontsov, IOP Conference Series: Earth and Environmental Science 403, 012116 (2019) doi:10.1088/1755-1315/403/1/012116

10. A.A. Kotesova, S.V. Teplyakova, S.I. Popov, F.C. Kopylov, IOP Conference Series: Materials Science and Engineering 698, 066029 (2019) doi:10.1088/1757899X/698/6/066029

11. V.V. Ivanov, S.I. Popov, A.V. Kirichek, IOP Conference Series: Materials Science and Engineering 327, 032026 (2018) doi:10.1088/1757-899X/327/3/032026

12. V.V. Ivanov, N.S. Dontsov, A.V. Kirichek, IOP Conference Series: Materials Science and Engineering 327, 032025 (2018) doi:10.1088/1757-899X/327/3/032025

13. V.V. Ivanov, N.P. Pogorelov, N.S. Dontsov, Y.N. Denisenko, AIP Conference Proceedings 2188, 020005 (2019) doi.org/10.1063/1.5138379

14. D. Evseev, A. Kotesova, V. Kosenko, A. Golubeva, IOP Conference Series: Materials Science and Engineering 698, 066032 (2019)

15. V. Kasyanov, V. Deryushev, L. Shulkin, E. Kosenko, A. Kotesova, MATEC Web Conf. 224, 02107 (2018) doi.org/10.1051/matecconf/201822402107

16. V. Deryushev, M. Zaitseva, G. Megera, A. Fedyanov, IOP Conference Series: Materials Science and Engineering 698, 066031 (2019)

17. T. Rogovenko, M. Zaitseva, Materials Science Forum 931, 417-421 (2018) doi.org/10.4028/www.scientific.net/MSF.931.417

18. N.N. Nikolaev, Yu.V. Marchenko, S.K. Filatov, IOP Conference Series: Materials Science and Engineering 698, 066027 (2019) doi:10.1088/1757-899X/698/6/066027

19. A. Khoroshev, A. Pavlenko, A. Korotky, D. Tchout, V. Puzin, E. Khorosheva, IOP Conference Series: Materials Science and Engineering 177(1), 012072 (2017) doi:10.1088/1757-89 012072

20. V.A. Lebedev, V.V. Ivanov, V.P. Fedorov, Materials Science and Engineering 124 (2016) doi:10.1088 / 1757-899X / 124/1/012160. R.1-6

21. V.P. Smolentsev, A.I. Portnykh, V.V. Ivanov, IOP Conf. Series: Materials Science and Engineering 327, 042121 (2018) doi: 10.1088 / 1757-899X / 327/4/042121

22. S.I. Kambulov, I.V. Bozhko, A.V. Olshevskaya, MATEC Web of Conferences 224, 05022 (2018) https://doi.org/10.1051/matecconf/201822405022

23. A. Altybayev, A. Zhanbyrbayev, B. Meskhi, D. Rudoy, A. Olshevskaya, A. Prohorova, E3S Web of Conferences 135, 01078 (2019) https://doi.org/10.1051/e3sconf/201913501078

24. B. Meskhi, B. Golev, V. Efros, D. Rudoy, A. Olshevskaya, V. Zhurba, Y. Chayka, E3S Web of Conferences 135, 01083 (2019) https://doi.org/10.1051/e3sconf/201913501083

25. J. Gerber, A. Zavaly, A. Gavrilov, A. Olshevskaya, N. Kiyan, IOP Conf. Series: Earth and Environmental Science 403, 012014 (2019) doi:10.1088/1755-1315/403/1/012014

26. G. Parkhomenko, S. Kambulov, A. Olshevskaya, A. Babadzhanyan, N. Gucheva, I. Mekhantseva, IOP Conf. Series: Earth and Environmental Science 403, 012144 (2019) doi:10.1088/1755-1315/403/1/012144

27. A.A. Kostoglotov, D.S. Andrashitov, A.S. Kornev, S.V. Lazarenko, Measurement Techniques 62, 497-502 (2019) DOI: 10.1007/s11018-019-01652-8 
28. S.V. Lazarenko, A.A. Kostoglotov, Journal of Communications Technology and Electronics 62(2), 123-127 (2017) DOI: 10.1134/S1064226917020061

29. A.A. Kostoglotov, I.V. Pugachev, S.V. Lazarenko, AIP Conference Proceedings (2019) DOI: $10.1063 / 1.5138398$

30. S.V. Lazarenko, A.A. Kostoglotov, A.I. Kostoglotov, Journal of Communications Technology and Electronics, 54(4), 431-438 (2009) DOI: $10.1134 / \mathrm{S} 1064226909040081$ 